\title{
MULHER DE FÉ SUJEITO DE QUEM: O IMPACTO DA TEOLOGIA FEMINISTA NAS PRESCRIÇÕES DO COMPORTAMENTO FEMININO A PARTIR DE UMA IGREJA LOCAL
}

\author{
Amanda da Silveira Borges ${ }^{1}$
}

Resumo: As transformações que as lutas femininas têm causado na sociedade afetam principalmente dois campos, os quais serão especialmente tratados nesse trabalho. Elas inserem-se no campo religioso e no campo político a partir da perspectiva de gênero. Nesse sentido foi analisado como estão acontecendo, ou não acontecendo, as transformações no campo religioso evangélico, especificamente, no que diz respeito à mulher em uma igreja evangélica local. Qual a representação feminina neste tempo, marcado pela diversidade nos discursos e singularidades de uma Teologia Feminista mais fortalecida, dentro da igreja evangélica. A partir da observação das práticas e rituais na igreja evangélica Brasa de Porto Alegre e da análise de entrevistas, foi possível perceber o distanciamento entre o protagonismo feminino buscado pela Teologia Feminista e a representação das prescrições de comportamento esperados das mulheres evangélicas neste espaço.

Palavras-chave: Mulher; Igreja; Feminismo; Teologia Feminista.

Por muitos séculos desde a Revolução Industrial as mulheres vêm reivindicando seu espaço na sociedade, de fala, de trabalho e de decisões. Com o passar dos anos esses espaços vêm sendo ampliados, de forma lenta, porém uma maior visibilidade e engajamento na temática feminista têm sido crescente.

Levando em consideração o avanço das mobilizações e as transformações geradas por elas, organizo de forma cronológica um paralelo que existe entre as diferentes fases do Feminismo no Brasil com a construção da Teologia Feminista. A partir desses dois campos de análise pode-se depreender o quanto a construção de mundos simbólicos em uma trajetória histórico-política avança com novos direitos conquistados às mulheres. É interessante observar que as questões do ideário feminista trato como ideário as principais lutas dos movimentos feministas - fazem atravessamentos constantes durante a construção da Teologia com esse viés no Brasil. Teologia de mulheres primeiramente católicas que não pretendem romper com sua fé e

Bacharelanda em Sociologia na Universidade Federal do Rio Grande do Sul - UFRGS.
e-mail: amanda.silveira@ ufrgs.br 
nem com a igreja, contudo assumem o teor político que a religião enseja, carregado na Teologia da Libertação ${ }^{2}$, que teve início na América Latina influenciada pela teoria marxista de luta por igualdade e a favor dos oprimidos. Nessa mesma época, na década de 1970 inicia a participação brasileira nas discussões internacionais sobre a questão da mulher. Em 1975 acontece no México, a Conferência Mundial sobre a Mulher, tratando de três eixos principais: 1) a igualdade plena e a eliminação da discriminação por motivos de gênero; 2) a integração e plena participação da mulher no desenvolvimento; e 3) uma contribuição a cada vez maior da mulher ao fortalecimento da paz na sociedade internacional. Dessa forma, vemos a mulher no centro de um eixo espiral conceitual que vem mobilizando transformações na estrutura social, que ora afeta e ora é afetada por essas mudanças. Para compreender esse processo histórico que se desloca para o interior da igreja evangélica e tem permeado os discursos com um intento de busca da igualdade e ao mesmo tempo espaço para o diferente em uma cultura que tende a uniformização de seus seguidores. Utilizo-me para tal análise de Bourdieu e sua teoria sobre os campos, Heidegger como base da hermenêutica para explicar a lógica no discurso da hermenêutica da suspeita adotada pelas Teólogas Feministas, dentre outros teóricos como Foucault e Fraser, e, assim, divido em duas partes a análise desse estudo. Na primeira parte: as transformações da igreja e como a mulher é situada nesse processo e na segunda: a atualidade com a Teologia Feminista e o distanciamento desse discurso com na igreja local, Brasa.

\section{A Mulher e a Igreja}

Ao longo dos anos as mulheres são vistas dentro de uma cultura ocidental androcêntrica como humanos de menor importância e clinicamente instáveis, relegadas a papéis subalternos em relação aos homens (Laqueur, 2001). Esse pressuposto ganha enorme força quando amparado pelo âmbito religioso, assumindo uma força simbólica que permeia o político ao longo de décadas. Tal afirmação é vista se analisarmos a história da igreja, a qual vem contribuindo substancialmente durante, e pós era vitoriana, para a aceitação hegemônica deste padrão segundo Foucault (2010). Embora hoje exista uma gama enorme de diferentes denominações e vertentes que por sua vez ressignificam

2 A Teologia da Libertação é uma corrente teológica doutrinária, que ganha força no interior da igreja católica a partir de 1960. É vista como uma reinterpretação analítica e antropológica da fé cristã, voltada aos problemas sociais existente em particular na América Latina. Parte da premissa de que o evangelho está voltado preferencialmente aos pobres e especifica que a teologia, pode lançar mão das ciências humanas e sociais. 
o texto bíblico de acordo com os tempos vividos, ainda é um tabu que a mulher seja ouvida nas esferas decisórias e que a ela seja dado poder.

No intento de tensionar e movimentar essas estruturas algumas mulheres do meio evangélico têm reagido a essa posição de subalternas e se movimentado para combater esses padrões, assumindo um posicionamento a respeito de sua representação nesse meio e produzindo conhecimento bíblico à luz de uma abordagem feminista de gênero, criando artigos e uma Teologia Feminista que denuncia e gera desconforto nesse ambiente, reforçando de forma mais intensa o clima de disputa.

Não é nova a discussão de que as práticas da igreja refletem que à mulher, e agora passaremos a análise das prescrições do comportamento da mulher evangélica, atribui-se o papel do doméstico, aquela que permanece segura por um ambiente privado tendo sua liberdade questionada mesmo neste espaço. Gostaria de ressaltar ainda o caráter doméstico à luz de Okin (2008), imbricado nas práticas da mulher evangélica em relação a seu comportamento, que deve ser da mulher para o marido, e aqui cabe usarmos o termo da teóloga feminista Elisabeth Schüssler Fiorenza, kyriarcado ${ }^{3}$, pois é natural que o corpo careça de uma conduta moralizante e seja visto como inferior. Dentro dessa concepção de corpo destrutivo da ordem, neste caso o não falar e a repressão tornam-se as principais formas de agir em relação ao corpo e a sexualidade desenvolvida nestes, assim como o papel político e decisório da mulher dentro do contexto evangélico tradicional ${ }^{4}$ torna-se nulo, vindo a refletir uma trajetória contida voltada para a família e vida na igreja. O que fica amparado na lógica vitoriana destacada por Foucault (2010), pois por anos essa moldura patriarcal tem disseminado os ensinamentos bíblicos de forma rígida, unilateral e conformatadora das diferenças, "Ao que sobra só resta encobrir-se; o decoro das atitudes esconde os corpos, e a decência das palavras limpa os discursos" (Foucault, 2010. p.10). A mulher está subordinada à família e ao poder do homem como veremos na segunda parte com as entrevistas, legitimada pela instrução cristã também dentro da esfera doméstica. É interessante perceber que o exercício político da mulher fica altamente comprometido uma vez que esse comportamento pressupõe regras reguladas também pela noção de “experiência” com Deus, pois a debilidade nesta relação Deus X fiel é que demonstraria o comportamento desviante. Logo, os mecanismos de controle estão para além do discurso regulatório, mas também, em uma certa medida, aferição de intensidade, da

3 Termo cunhado em 2001 por Fiorenza, o qual redefine a categoria analítica patriarcado, unindo as palavras gregas kyrios (senhor/mestre) e archein (gobernar/dominar) para definir a forma kyriarcal como algumas igrejas lidam com o feminino em suas denominações.

$4 \quad$ tradicional aqui refere-se tanto às igrejas de matrizes históricas quanto pentecostais ou neopentecostais. 
experiência religiosa ao ponto da transformação de suas práticas exemplificando a teoria dos campos de Bourdieu, conforme Ortiz (1983) onde os atores estão em constante disputa em relações assimétricas. Por conta dessa concepção em relação à mulher foi que os movimentos feministas desde os anos 60 buscaram as transformações sentidas hoje em diversas áreas da sociedade, conquistando avanços na área dos direitos humanos com a inserção do Brasil em discussões internacionais a respeito dos direitos da mulher. No lastro desses acontecimentos há a mobilização de mulheres católicas atuantes nas Comunidades Eclesiais de Base, engajadas no ideário da Teologia da Libertação, a qual antecede a organização da Teologia Feminista no Brasil, valendo-se da mesma base marxista tomada pelo feminismo e outros movimentos sociais da época.

Relação entre as linhas do tempo das transformações na Teologia Feminista e Feminismo no Brasil.

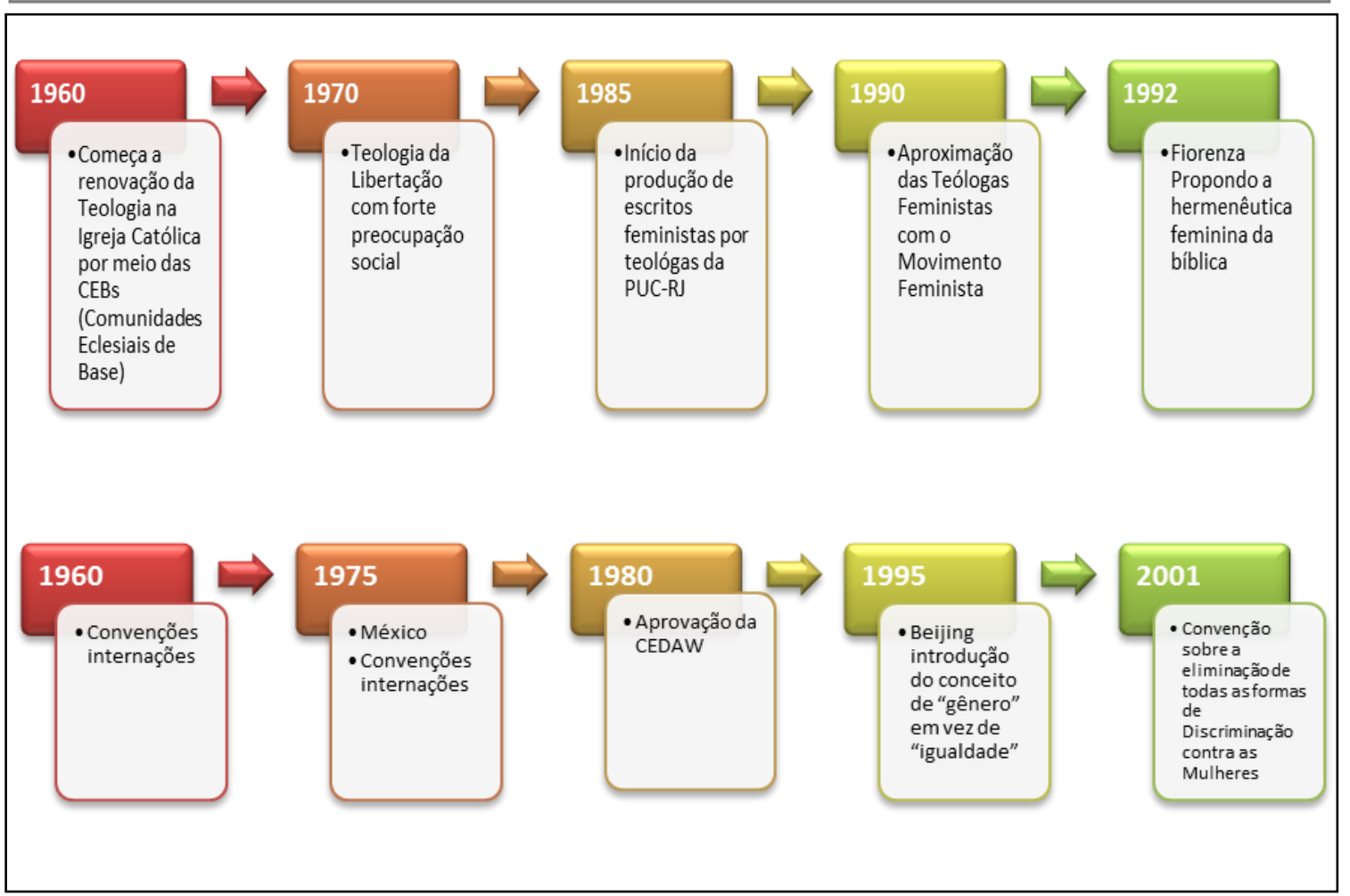

Fontes: Catolicismo e protestantismo: O Feminismo como uma questão emergente. ROHDEN, 1997; Os direitos Humanos na Perspectiva de Gênero. BARSTED, 2001.

Essas transformações puderam ser sentidas inclusive no universo do trabalho, com a forte ocupação das mulheres. Foram essas transformações em padrões culturais e valores relativos ao papel social da mulher que oportunizaram novos horizontes, alterando a constituição da identidade feminina (Bruschini, 2002). É possível hoje perceber os efeitos de uma transformação iniciada também na década de 70 na América do Norte, quando se passou a propor uma Teologia Feminista. Desses mesmos ideais 
partilham hoje mulheres brasileiras dentro das diferentes igrejas, e, mesmo que haja alguns limitadores para as suas ações, é essa força mobilizadora que tem reunido algumas mulheres a buscar uma transformação nos discursos, o que impacta diretamente a estrutura conhecida da igreja, como propõe Ivone Gebara e Odja Barros, fortes expoentes católica e protestante da defesa da igualdade da mulher no contexto cristão. Dentre outras, elas têm buscado desfazer os discursos e ensinamentos tendenciosamente patriarcalistas, através de uma hermenêutica da suspeita, trazendo novas formas da interpretação dos textos bíblicos sem apagar a participação e nem o protagonismo feminino das histórias bíblicas segundo Barros: "Ouvir as vozes silenciadas das mulheres na Bíblia que deixaram suas mensagens criptografadas em seus corpos, em suas histórias" (Barros, 2010).

\section{A Igreja Brasa X a Teologia Feminista}

A partir da pesquisa feita na igreja Brasa $^{5}$ em Porto Alegre, busquei compreender como as temáticas feministas, e, agora presentes em uma teologia, se fazem valer ou não, no ambiente da igreja local. Sendo essa uma igreja que originou-se de uma Batista com tradição protestante histórica e se inseriu fortemente nas mídias sociais de internet e renovou sua estética criando um culto voltado ao público jovem denominado Brasa Church, ganhando grande adesão do público jovem. Por conta de sua forte atuação e divulgação na internet, isso veio ao encontro do interesse em compreender até onde o novo teria ganhado sentido nos discursos eclesiais. O segundo ponto forte para a escolha por essa igreja, é que hoje o lugar de maior propagação da Teologia Feminista são as redes sociais, tanto com páginas publicando os textos acadêmicos produzidos por teólogas, quanto para debates e divulgação do viés favorável a mulher contido na bíblia.

No terceiro ponto, a Brasa é uma das igrejas em Porto Alegre que possui uma mulher como membra do núcleo de pastores. Essa igreja divide-se em dezoito ministérios, entre eles: escola de ensino fundamental, surdos, línguas, teatro, música, casais, crianças, mulheres, dentre outros. Cinco destes são liderados por mulheres, e ainda, dentre o núcleo de pastores, cinco são homens e uma é mulher. Nota-se que embora haja uma pastora e que ela faça parte do presbitério da igreja, sua atuação não é

5 O Ministério Brasa surgiu no ano de 1986 em Porto Alegre. Onde membros de uma igreja Batista tradicional, que já existia há 76 anos tiveram experiências espirituais incomuns em um ambiente tradicional. O que levou a criação da nova denominação, que entraria no rol de Batistas avivadas ou renovadas, hoje conhecida como Brasa. 
muito expressiva, demonstrando que a simples aceitação de mulheres em cargos pastorais não elimina o estigma carregado pela mulher, como sendo aquela responsável pela queda da humanidade e que deve ser tratada como submissa, tal como interpretado das cartas paulinas. Atribuir essa representação à mulher demonstra a força do campo instituído sob a lógica kyriaka, onde o homem é colocado como o redentor e a mulher a parte a ser redimida, conforme a fala de uma das entrevistadas.

\begin{abstract}
Mesmo com todas as transformações que ocorreram nos últimos anos, ainda é raro, hã...ter mulher em cargo de liderança, a menos que esse cargo seja voltado para as mulheres. Como por exemplo...hã...sei lá...ser líder de grupo das mulheres, entendeu? Líder do grupo de dança! Né? Inclusive, em toda Brasa, só tem uma pastora, uma mulher...E aí a gente tá falando de uma igreja que tem...não sei quantos anos hoje, e eu tô falando da Brasa em termos de sistema, porque ela tem igrejas espalhadas, muitas igrejas espalhadas, por todo o Rio Grande da sul e na Europa e... as mulheres têm esse papel sempre secundário...tem uma pastora apenas que quando ela foi separada para o ministério, o pastor falou que era contra...hã...ordenação feminina, mas, que ele via e que ele sabia que Deus tinha aquilo pra ela, e que ele não tinha mais como fugir daquilo, ele falou exatamente isso, com essas palavras. Ele não tinha como negar o mover de Deus na vida daquela mulher, embora ele como homem e pastor não concordasse. Então todos os cargos que as mulheres ocupam, são cargos com exceção dessa pastora, são cargos que visam o cuidado com a própria mulher, então não são cargos de liderança...hã...sobre homens, por exemplo. [...] as pessoas já viam ela como uma pastora, eu acho que no caso dela foi apenas um ato simbólico, mas eu não sei como que ela lida sendo uma mulher em um cargo só de homens, majoritariamente homens, não sei se a voz dela é silenciada ali...se ouvem ela...eu não tenho ideia de como isso funciona pra ela no presbitério. O que eu posso dizer é que a gente ouve ela muito pouco! Ela pregando na igreja...ouvir o nome dela, como a gente ouve dos outros pastores... é muito raro, a gente quase não ouve falar dela. Tem pessoas que hoje chegam lá que não sabem que tem uma pastora, é complicado.
\end{abstract}

Nessa fala, assim como em outras, é visto que o alcançar da mulher aos postos de poder dentro da igreja não significa que lhe tenha sido atribuído autoridade, não em relação aos homens. Aparecendo de forma assimétrica a relação conflituosa do campo, onde os recursos são limitados e dificilmente questionados por parte das mulheres, pois o questionamento pode ser interpretado como insubmissão ou irreverência a uma figura instituída por Deus, o pastor. Gebara critica essa postura patriarcal quando coloca:

\footnotetext{
"A sociedade patriarcal, cujas raízes dificilmente conseguiremos detectar produziu sua antropologia, seu modelo de homem e mulher e a partir dele, de certa forma, organizou a sociedade. Vivemos ainda nesse modelo de características hierárquicas, idealistas e excludentes. Não que ele se define a partir dessas características, mas são elas que aparecem à primeira vista quando tentamos compreender o homem e a mulher produzidos por nossa atual cultura. $\mathrm{O}$ modelo antropológico patriarcal se desdobrou na história do ocidente em muitas formas e foi o responsável pela "produção" de uma série de comportamentos ideológicos que justificaram múltiplas explorações desde o colonialismo, o racismo e a dominação na relação homem e mulher". (Gebara, 1987)
} 
Podemos dizer que o bem-alvo em disputa no campo neste momento é o do prestígio ou reconhecimento, onde a estrutura organizada hierárquica e patriarcalmente da igreja busca a manutenção de seu status dominante. A busca das mulheres por força de argumentação contra essa lógica, se dá no instrumento formador da sociedade ocidental e cristã para manutenção dessa exclusão, a própria bíblia. Com uma proposta da hermenêutica da suspeita as teólogas feministas utilizam uma exegese a partir da desconstrução da lógica interpretativa nos textos bíblicos, feita a partir de uma concepção feminista. Esse tipo de interpretação em muitas vezes é visto como uma perversão do relato bíblico, mantendo assim a imutabilidade das regras do jogo.

A hermenêutica da suspeita herda do conceito de Heidegger, a qual está voltada para uma abordagem fenomenológica da sociedade conceituada por ele como: "descrever o mundo fenomenologicamente significa: mostrar e fixar numa categoria conceitual o ser dos entes que simplesmente se dão dentro do mundo." A partir da hermenêutica da suspeita passa-se a valorizar o papel da mulher definindo essa teologia como imanente nos relatos bíblicos, porém suprimido. Barros aponta que o exercício para essa construção deve ser constante.

\footnotetext{
“Aprender essa dança hermenêutica é um desafio para nós mulheres e homens que acreditamos na igualdade e justiça das relações, e para nós que apesar de reconhecermos o problema patriarcal da Bíblia, continuamos vendo nela também a Revelação de Deus para mulheres e homens". (Barros, 2010) ${ }^{6}$
}

Dar novas interpretações à bíblia implica em construir novos espaços democráticos onde caibam todos e todas, de diferentes raças, etnias, sexo e classe social. Fica clara a relativização do sexo e da sexualidade pelas Teólogas Feminista, temática de grande disputa no meio evangélico, opondo-se aos binarismos de macho e fêmea aceitos pela igreja de forma geral. Há aqui uma nova proposta de relação com o corpo e suas formas, uma forma mais livre de punições na aceitação das diferenças.

Ao longo da descrição dos métodos adotados para essa nova interpretação dos escritos sagrados, percebe-se que o corpo feminino já não é mais tido como aquele que necessita da correção ou decoro, tratado como inatamente imoral, mas é esse mesmo corpo que de forma holística reinterpreta e vive esse novo entendimento. Não seria possível redimir o feminino sem redimir o que dele é intrínseco.

\footnotetext{
6 Barros, 2010. Disponível em: < http://novosdialogos.com/lendo-a-biblia-a-partir-da-perspectivada-mulher/> acesso: Jul/2017.
} 


\begin{abstract}
“Assim é que se diz que a leitura da Bíblia a partir das mulheres se assemelha a um diálogo corpo a corpo. Essa leitura favorece a construção de significados e sentidos mediante uma dinâmica de intertextualidade entre dois corpos. O nosso corpo, a nossa vida e experiência entram em diálogo com a vida, a história e os corpos das mulheres da Bíblia". (Barros, 2010)
\end{abstract}

Outra unidade para o entendimento do universo da mulher na igreja Brasa que não dialoga com a Teologia Feminista é a da mulher como aquela que pertence ao ambiente doméstico, mostrando que há uma necessidade do ensino do trabalho doméstico principalmente às jovens casadas há pouco tempo. Ou seja, uma tendência a manutenção da divisão sexual do trabalho é identificada aqui, pois é necessário que as jovens esposas aprendam os afazeres domésticos, principalmente se esse for motivo de brigas entre os casais. Segundo diálogo com uma das líderes do grupo de mulheres da igreja, o grupo existe para apoiar e ensinar umas as outras, também como um incentivo a oração e adoração a Deus de novas e velhas convertidas. O grupo de mulheres torna-se um espaço de cumplicidade, de compartilhamento das dificuldades e de oração e pouco a pouco conquistou um espaço reconhecido pelos demais membros da igreja, devido ao seu envolvimento em várias causas sociais. Aos homens por sua vez é ensinado que ajudem suas esposas nos afazeres no intuito de fazer com que suas esposas fiquem felizes e não por fazerem-se tão responsáveis pelos trabalhos domésticos quanto suas esposas.

[...] é...a mulher é sempre vista como acessório, auxiliar do trabalho dos homens. Hã as questões voltadas pra mulher lá, são desse cunho, como ser uma melhor esposa, como ser melhor mãe, é...como ela poderia auxiliar o seu marido no trabalho, no ministério, todas as questões, é... frisavam isso, nunca sobre como as mulheres podem ter autonomia, por exemplo. E continua sendo assim, a mulher sempre sendo vista e sendo trabalhada dessa forma...

A autonomia citada pela entrevistada expõe que há uma fragilidade na estrutura da igreja que não reconhece a mulher como profissional atuante e inserida no mercado trabalho. Aqui se coloca um ponto de intersecção bastante relevante no sentido de que o sucesso profissional seja algo valorizado, tanto ao homem quanto à mulher, no entanto, sobre a mulher recai a responsabilidade do lar e dos filhos. Mesmo com a colaboração do marido no cotidiano familiar a responsabilidade continua sendo feminina ao ponto de fazer parte da rotina da igreja esse ensinamento, o que se assemelha muito ao quadro da mulher trabalhadora brasileira de forma geral. As mulheres embora em crescente ocupação aos cargos de trabalho produtivo, ainda carregam a forte atribuição aos trabalhos de cuidado, o que torna a mulher, mais uma vez, ocupante em lugar de relações assimétricas quanto a produção e a própria realização pessoal para com suas 
atividades. Neste ponto vale fazermos um paralelo com o perfil das mulheres estado unidenses, as quais cresceram em número nas igrejas evangélicas se colocando debaixo de uma cultura da domesticidade. Essa aceitação da cultura evangélica não pressupõe, no entanto, que elas vivam vidas patriarcalistas, pois possuem certo empoderamento financeiro no ambiente familiar (Fraser, 2007). O contraponto se dá nas diferentes condições de acesso a esse emprego e nas diferenças estruturais econômicas e sociais da sociedade Norte Americana em relação a América Latina. A primeira conseguiu estabelecer suas políticas de bem-estar social para mais tarde adotar uma política liberal, no entanto, no Brasil a direta passagem ao liberalismo tem cada vez mais agravado os problemas de desigualdade social, colocando os menos favorecidos na linha de frente das dificuldades não sendo possível que o empoderamento feminino aconteça pelo viés econômico na maioria dos casos. Porém, o paralelo pode ser relevante no sentido de que tanto as mulheres norte-americanas quanto as brasileiras encontram na igreja evangélica um importante apoio para suportar a instabilidade e insegurança social que se agrava cada vez mais (Fraser, 2007). Esse caráter pacífico entra em oposição aos ideais da Teologia Feminista, a qual busca a transformação, a desconstrução e reconstrução das igualdades, embora a proposta de Gebara seja uma Teologia Feminista criadora de uma nova consciência a respeito das relações de poder nas diferentes esferas sociais e a partir da mulher e suas lutas.

\section{Conclusão}

Após um período de acompanhamento das práticas da Igreja Brasa em Porto Alegre, foi possível verificar que a igreja continua a passar por modificações em sua estrutura, na sua estética e tipo de apelo aos que se inserem em seu contexto, possivelmente esse mesmo fato possa ser observado em outras denominações da mesma forma. Porém as bases que instituem a doutrina, as quais podem não ser necessariamente as mesmas da bíblia, acabam por não se alterarem, ou quando são alteradas o fazem mediante pequenas concessões e negociações, mesmo que estas estejam colocadas em um mundo simbolicamente construído e que suas regras sejam dadas continuamente por um determinado perfil, o masculino visto como o normatizador. Há de novidade para a contemporaneidade a respeito das transformações possíveis advindas de dois campos: um o da religião agindo internamente na tentativa de reinventar as regras postas por centenas de anos. Esse apresenta grandes dificuldades 
em sua efetiva ação para que se torne como um discurso real e possível, o qual deixa o campo das discussões intelectuais e se coloca como uma nova chave à educação social a respeito da importância das questões próprias ao feminino. Considerando sempre os diversos grupos que se coadunam nas mesmas lutas por igualdade e visibilidade como os negros, as mulheres do campo e da cidade, os indígenas e demais minorias.

O segundo campo insere-se na importância da mulher em sua relação com as atividades produtivas relacionadas ao trabalho em sua forma remunerada, juntamente com a descoberta de si nessa atuação, podendo ser vista como efetiva forma de empoderamento e realização pessoal. De forma alguma pretendo criar uma dicotomia em relação ao que concerne à realização da mulher enquanto indivíduo, aludindo a um reducionismo no entendimento das fontes de descoberta e empoderamento da mulher em sua trajetória de vida. Mas no sentido de que seja possível à mulher fazer escolhas sem que o fato de ser mulher gere constrangimentos ou limitações para tal, neste contexto evangélico. A percepção em relação à mulher evangélica que trabalha não pode mais ser vista como uma situação não ideal ou que é aceita por conta da necessidade financeira da família, mas como opção possível.

Os campos compreendidos por essa análise comprovaram as hipóteses exceto na percepção das razões da crescente adesão de mulheres ao evangelho. Esse dado surge como novo axioma da análise, uma vez que o sentimento de pertença, apoio e cuidado recebido na igreja evangélica suprime as liberdades cerceadas fazendo com que sejam aceitos como parte das regras do jogo. De certa forma a adesão das mulheres a um sistema de dominação pode estar diretamente ligado com a teoria dos campos, pois uma das regras colocadas por Bourdieu para a caracterização deste é de que as tensões aconteçam e sejam aceitas como favoráveis pelos agentes causadores de tensão ao ponto que o campo não seja destruído. Ou seja, a tensão das disputas nunca deve exceder o limite do campo, o que faz com que as mulheres oponham-se em questões específicas mas, não ao ponto de uma incisiva disputa para o rompimento da fé.

A aceitação do trabalho profissional das mulheres por questões econômicas também exemplifica a dominação do capital, não sendo mais possível colocar-se contra o trabalho de produção da mulher nas igrejas evangélicas, como em momentos históricos anteriores. Foi percebido no paralelo estabelecido entre a linha do tempo do feminismo e da construção da teologia feminina no Brasil, que os avanços do feminismo continuam a acontecer, enquanto o avanço da Teologia Feminista é lento, truncado e sua capacidade de renovação com novos nomes tratando do tema é bem pequena. Esse fato contribui consistentemente para o não alcance desses ensinos nas 
igrejas locais, fazendo da internet o porta-voz de disseminação de novos estudos. A restrição da divulgação na internet por si só constitui um corte de público que alcança determinado perfil, trazendo mais um ponto em comum com o feminismo e suas origens.

A partir do entendimento dessas questões fica difícil dizer quais rumos a Teologia Feminista pode ainda tomar no Brasil, uma vez que a igreja como estrutura de apoio às mulheres cumpre bem o seu papel e está chancelada em suas formas pelas próprias mulheres. 


\section{REFERÊNCIAS BIBLIOGRÁFICAS}

BOURDIEU, Pierre. A Distinção: Crítica Social do Julgamento. São Paulo: Edusp/Porto Alegre: Zouk, 2007.

FOUCAULT, Michel. História da sexualidade I: a vontade de saber. Rio de Janeiro, Graal, 2010. Capítulos I; IV e V.

LAQUEUR, Thomas. Inventando o sexo: corpo e gênero dos gregos a Freud. Rio de Janeiro: Relume Dumará, 2001 [1990]. Cap. I

OKIN, Susan Moller. "Gênero, o público e o privado." Revista Estudos Feministas, Florianópolis, 2008, vol.16 (2), p.305-332.

BRUSCHINI, Cristina. Trabalhadoras brasileiras dos anos 90: mais numerosas, mais velhas e mais instruídas. 2002. v.2. Disponível em: 14/06/2017 <http://cdn.fee.tche.br/mulher/2002/artigo5.pdf $>$.

ORTIZ, Renato. (org.), Coleção Grandes Cientistas Sociais. Pierre Bourdieu. São Paulo: Ática. 1983.

GEBARA, Ivone. Teologia em ritmo de Mulher. Coleção mulher: tema atual. São Paulo: Edições Paulinas, 1994.

GEBARA, Ivone. Desafios que o movimento feminista e a teologia feminista lançam à sociedade e às Igrejas. Palestra proferida na Escola Superior de Teologia da IECLB, São Leopoldo, jun/1987.

TOMITA, Luiza Etsuko: A Teologia Feminista Libertadora: Deslocamentos Epistemológicos. In: Fazendo Gênero 9: Diásporas, Diversidades, Deslocamentos. Florianópolis: Universidade Federal de cSanta Catarina, 2010. Disponível em: $14 / 06 / 2017$

<http://www.fazendogenero.ufsc.br/9/resources/anais/1278455084_ARQUIVO_FAZE

NDOGENERO.final.pdf >

FRASER, Nancy. Mapeando a imaginação feminista: da redistri- buição ao reconhecimento e à representação. Estudos Feministas, Florianópolis, v. 15, n. 2, p. 291-308, mai./ago. 2007.

HEIDEGGER, Martin. A interpretação da pré-sença pela temporalidade e a explicação do tempo como horizonte trancendental da questão do ser In: Ser e tempo. Parte I. Tradução Márcia de Sá Cavalcante. Petrópolis: Vozes, 1997. 